\title{
An outdoor Test Reference Environment for double skin applications of Building Integrated PhotoVoltaic Systems
}

\author{
J.J. Bloem ${ }^{\mathrm{a}}$, C. Lodi ${ }^{\mathrm{b}, *}$, J. Cipriano ${ }^{\mathrm{c}}$, D. Chemisana ${ }^{\mathrm{b}}$ \\ a European Commission DG JRC, via E. Fermi 2749, TP 450, 21027 Ispra (VA), Italy \\ ${ }^{\mathrm{b}}$ Applied Physics Section of the Environmental Science Department, University of Lleida, c/Jaume II 69, 25001 Lleida, Spain \\ c CIMNE, Building Energy and Environment Group, c/Dr Ulles 2, 08224 Terrassa, Spain
}

\section{A R T I C L E I N F O}

\section{Article history:}

Received 13 February 2012

Received in revised form 1 March 2012

Accepted 11 March 2012

\section{Keywords:}

Building Integrated PhotoVoltaic (BIPV)

systems

Harmonisation

Outdoor testing

Dynamic analysis

Modelling

\begin{abstract}
A B S T R A C T
This article presents and discusses an outdoor Test Reference Environment (TRE) for double skin applications of Building Integrated PhotoVoltaic (BIPV) Systems.

From the experience gained during the past 20 years in several EC research projects, an experimental tested design for a common Test Reference Environment is proposed. This outdoor test set-up allows the assessment of experimental data for electrical and thermal performance evaluation of photovoltaic systems integrated as double skin applications in the building envelope. The specific design of the Test Reference Environment makes it possible to study in a harmonised way through electrical and thermal energy flow analysis, the impact of different materials for PV modules and construction design of building envelopes. The energy balance for BIPV double skin applications is presented as well.

The experimental data has been used for validation of modelling work by several academic groups which has resulted in an improved knowledge on the heat transfer, in particular the convective heat exchange coefficient for the specific double skin boundary conditions.
\end{abstract}

(c) 2012 Elsevier B.V. All rights reserved.

\section{Introduction}

Building Integrated PhotoVoltaic (BIPV) systems are building components that combine other functions of the building envelope with electricity generation. Double skin applications of BIPV systems appear as an attractive strategy for achieving the requirements of the new EU directive on energy performance of buildings (EPBD) [1], in particular the integration of renewable energy technologies supporting the design of nearly-zero energy buildings (NZEB). Double skin BIPV systems may improve the energy performance of the building envelope by decreasing the transmission losses in winter and by reducing solar gains in summer. Apart from generating electricity, the pre-heated air may reduce the ventilation thermal losses and therefore the heating demand of the building. At the same time, the pre-heated air might be coupled with a heating and ventilation air-conditioning (HVAC) system. Furthermore, the ventilation air heat extraction may decrease the PV module temperature, which will result simultaneously in an increase of PV electrical efficiency. In any case, a correct evaluation of the overall energy balance of these integrated systems is very complex due to highly variable and dynamic aspects.

\footnotetext{
* Corresponding author.

E-mail addresses: cipriano@cimne.upc.edu (J. Cipriano), daniel.chemisana@udl.cat(D. Chemisana).
}

Over the last 20 years, different EC projects have investigated the possibility to develop a standard outdoor environment for the energy performance evaluation of double skin applications of BIPV systems, giving input to modelling and analysis work.

Starting from the first EC PASSYS projects (1986-1994), it was found that BIPV system evaluation requires the combination of well-controlled experimental measurements under real climatic conditions with detailed simulation techniques. The EC PV-HYBRID-PAS project [2] (1994-1998) was aimed at developing standardised test procedures for the overall energy performance evaluation of hybrid PV building components. Tests on hybridPV components were carried out with both natural and forced ventilation using PASLINK test cells located in several different climates. Within this project an initial set-up of an outdoor Test Reference Environment (TRE) was outlined. One of the conclusions drawn from this project was that outdoor measurements of the energy balance must be performed under well-described and controlled conditions in order to use the data to calibrate numerical models. The PASLINK project [3] aimed to define quality requirements for outdoor testing and evaluation. Several partners in the PASLINK network carried out for industry experimental testing of PV intended for building integration.

The need for well-described and standardised testing conditions was the core issue of the EC PRESCRIPT project [4] (1997-1999) regarding the development and benchmarking of a pre-standard for testing PV roofs and facades. In the context of this European project 


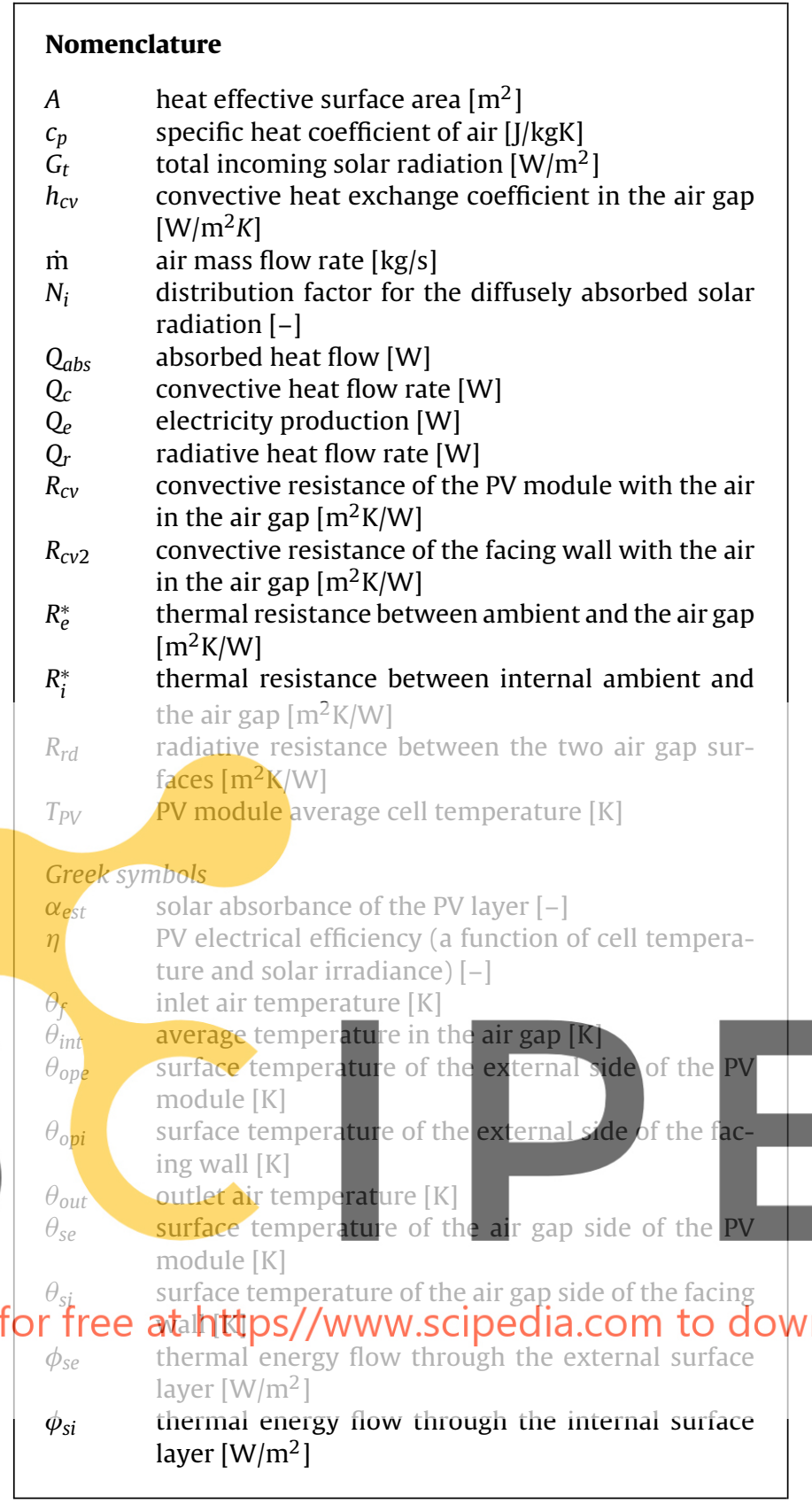

it was emphasised that standard test procedures, as described in IEC 61215 [5], are not directly applicable for BIPV systems.

The later EC IMPACT project [6] (1998-2000) studied the heat exchange of a PV module to its surroundings and the first version of an outdoor Test Reference Environment (TRE) for double skin applications of BIPV systems was built at the EC Joint Research Centre (JRC) of Ispra. The TRE was used to assess the thermal exchange of a PV module within the building envelope. The purpose of the experimental work on TRE was to obtain several data series for the same PV module under different boundary conditions and to compare them with data series from other PV modules. Reference mini-modules were specifically designed during this project, for testing the performance of similar PV module composition in fully insulated and free-rack conditions [7]. Several numerical models were developed by different authors [8-11] based on experimental data from the initial and improved version of the TRE.

A third and further improved version of the TRE was built in 2009 by the International Centre for Numerical Methods in Engineering
(CIMNE) and the University of Lleida (UdL) [12]. One of the most relevant improvements is the support structure which allows any inclination of the PV module to be tested, varying from horizontal to vertical. In Lleida, the energy performance of the PV module placed at the TRE opening is compared with that of two identical PV modules used as a reference, one fully insulated and the other under free-rack conditions. From the experimental campaign of the TRE of Lleida, other models have been developed by Lodi et al. [13].

From the experience gained with the 10-year experimental and modelling work on the TRE, this paper presents a proposal for a common Test Reference Environment for double skin BIPV systems. This paper proposes harmonised requirements and recommendations in order to define a common procedure for testing double skin BIPV systems in a well-controlled Test Reference Environment, thus providing suitable input for design and modelling work.

The recently started IEA ECBCS Annex 58 [14] offers the possibility to further develop practical solutions for BIPV double skin applications through outdoor testing and dynamic analysis methods.

\section{BIPV and harmonisation}

\section{1 \\ For a good understanding of the applications of PV in the built environment that are presented here, it is important to distinguish between the following applications:}

- PV rooftop and PV cladding façade applications use the building for the support structure while an impact on the energy system is not considered.

- BIPV covers PV technology integrated in the building envelope (roof or façade) giving impact to the overall energy behaviour and functionality of the bulding such as a roof construction element. Thus BIPV covers the application area where PV technology is an integra PV/T is the technology electrical and therpal nd could be integrat energy whic

Sometimes the terminology of hybrid PV is used; following the

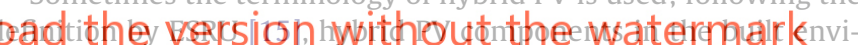
ronment are building elements in which the integration of PV technology not only serves for electricity production, but where the themal impact of the elements is also used for other purposes.

Building designers are interested in the performance under operating conditions for a typical climate, season and specific location taking into account the energy use of their design. Integration of PV in the building envelope implies that they not only have to take into account electrical energy production, but also thermal (avoiding overheating in summer) and comfort (daylight, ventilation and quality of air) aspects. A further consideration is that building designers need performance indicators based on climatic variables: ambient temperature, solar radiation, wind velocity and site dependent data such as obstructions giving possible shading problems.

PV components, integrated in a building's envelope, interact with the building in many respects. This is schematically shown in Fig. 1. A comprehensive assessment procedure should include the following aspects:

- Electrical performance

- Thermal processes at component level

- Seasonal dependency of the thermal performance

- Ventilation performance

- Visual performance 


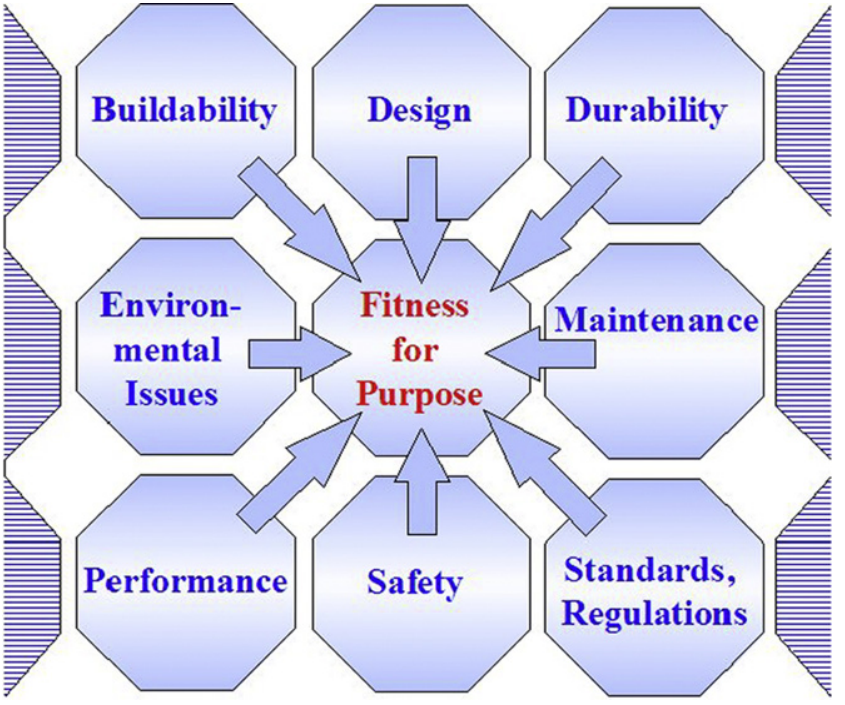

Fig. 1. Schematic presentation of different aspects for PV building integration [16].

- Maintenance related aspects and durability

- Other performance objectives

Aspects related to the electrical, thermal and ventilation performances are schematically presented in Fig. 2 and briefly described below.

\subsection{Electrical performance of BIPV elements}

The measurement of $t$ has already been standard element. If the absorbed so purposes in a hybrid compo efficiency due to the tenpe rial. The main technology is electrical performance of PV ele
ised to a large extent. The elect
endent on the temperature of
in heat is partially ecovered for
nent, then this will affect the elect
erature coefficient of the active
is that of wafer-based silicon PV
used in most common PV modu elements
electrical
of the PV
for other
electrical
tive mate-
PV cells 85\% in 2010 [17]), which is used in most common PV modules and has a negative temperature coefficient. Therefore a combined ther- necessary. With the PV-Hybrid-Pas project [2], outdoor test cells were used for a calorimetric assessment of a PV system under double skin conditions. During the IMPACT project [6], the TRE was used to assess the thermal exchange of the PV module with its immediate environment.

\subsection{Thermal processes at component level}

The following aspects are to be investigated:

- Dynamic aspects of heat transfer through the component in the situation without airflow in the cavity. The heat transfer is complex and is further described in.

- Overall energy performances for the test duration but also for standardised conditions. This requires the combination of realistic measurements with simulations, through so-called scaling and replication techniques.

- Dependency on component dimensions. The thermal buoyancy effects (and therefore also the electrical efficiencies) vary as function of the size (height) of the PV installation.

\subsection{Thermal performance in winter and summer}

The heat gained by PV modules solar absorption can be used for heating purposes of the spaces adjacent to these PV facades or roofs. The interaction with the space can be studied by outdoor testing of the component in test cells. Based on the results of the outdoor experiments, the effect of such components on real buildings and in various climates can be studied by simulation (scaling and replication) of the energy, ventilation and daylight performance. The thermal comfort in an adjacent room can also be evaluated [18].

The pre-heating of air under BIPV conditions is not always an advantage. In strmmer period, pre-heated air nay have a negative influence on the indoo climate. In practice/differen ventilation strategies fore required.

In addition, in the case of semi-transparent pV elements, heat lows can pass through the inner surface of the building component partly direct solar gains, partly by radiation due to the high surface temperature). This is an important effect, which is included in the

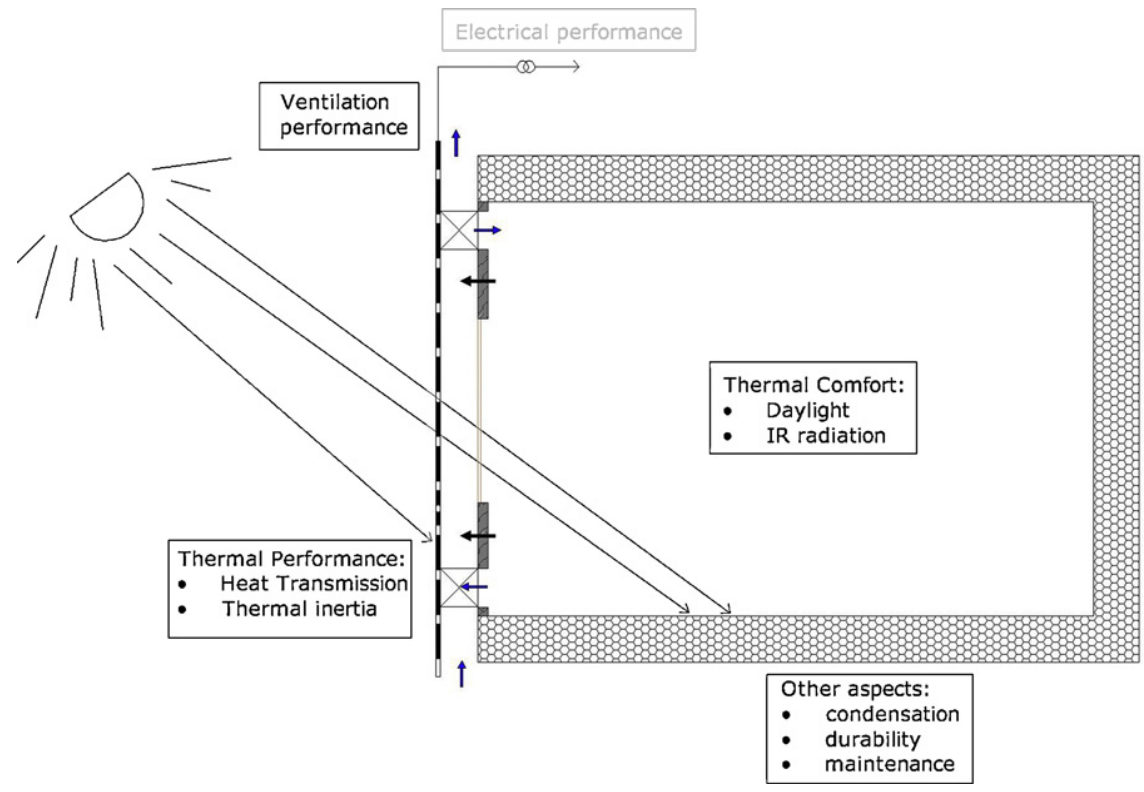

Fig. 2. Interaction of various phenomena for a PV component applied to a building envelope. 


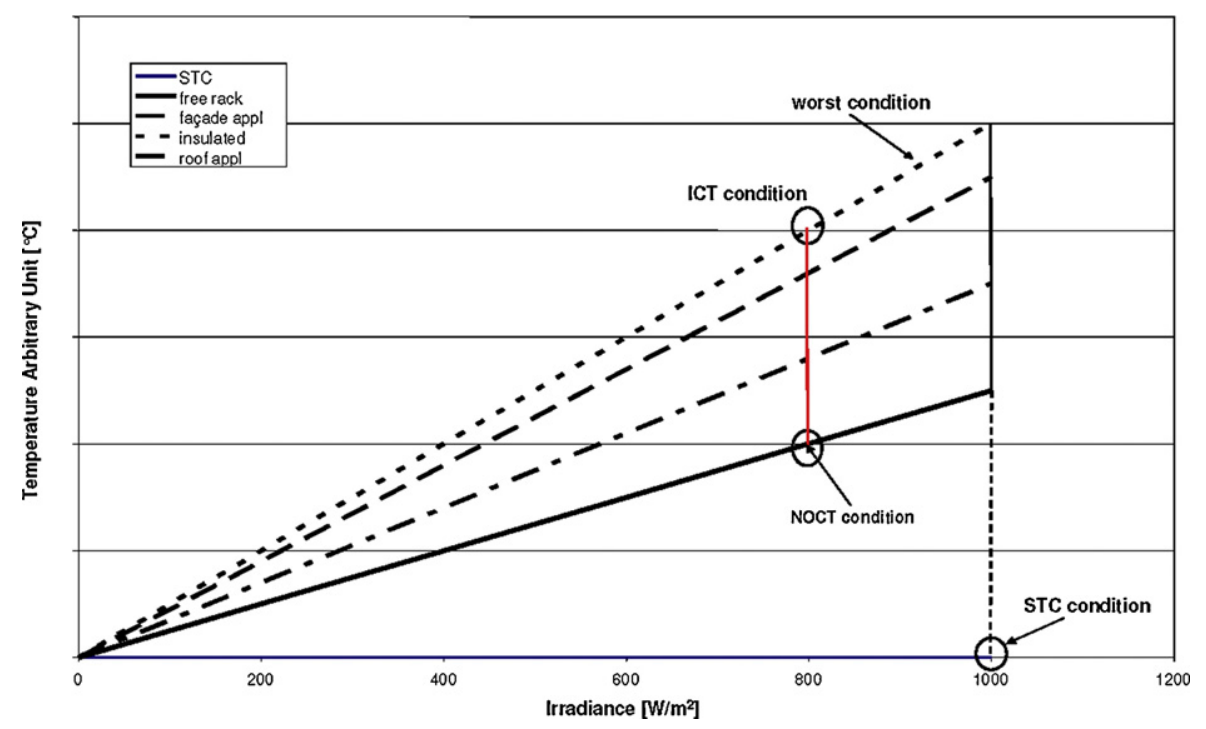

Fig. 3. Temperature difference versus irradiance [22].

\subsection{Ventilation performance}

The utilisation of warm air for the purpose of pre-heating, in particular for the colder season, needs an assessment of the ventilation performance of the integrated PV-installation. With respect to the procedures for evaluating the ventilation performance, a distinction must be made between two types of systems: from the Standard Reference Environment as described in the IEC 61215:

- The inclination for façade application is typically $90^{\circ}$, and for roof applications it depends on the roof construction but is seldom optimised.

- Free convection at the rear side of the PV modules does not occur

- Naturally ventilated systems. The airflow rate varies over time as a function of the outside dimate, the inside climate and the use of the building. Prediction of

- Mechanically driven systems be more or less constant and easier to make.

\section{The technical data provided by the PV industry are based on} standardised measurements under laboratory conditions described in IEC 61215 [5].

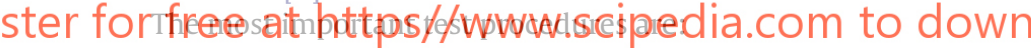

- 10.2 Standard Test Conditions (STC),

- 10.5 ivieasurement of iNominai Operating Celi Temperature (NOCT),

- 10.6 Performance at NOCT,

- 10.7 Performance at low irradiance.

Concerning 10.5, NOCT is defined as the equilibrium mean solar cell junction temperature within an open-rack mounted module in the following Standard Reference Environment (SRE):

- Tilt angle: at normal incidence to the direct solar beam at local solar noon

- Total irradiance: $800 \mathrm{~W} / \mathrm{m}^{2}$

- Ambient temperature: $20^{\circ} \mathrm{C}$

- Wind speed: $1 \mathrm{~m} / \mathrm{s}$

- Electrical load: 0 A (open circuit, thus no current flowing)

- Open rack mounted PV modules with optimised inclination.

Measurement of NOCT for PV modules applied as BIPV components are of most interest as the negative temperature effect on the maximum power is about $0.5 \% /{ }^{\circ} \mathrm{C}$ (referred to conditions at $25^{\circ} \mathrm{C}$ ).

A number of different circumstances occur when PV modules are applied as integrated components in a building, which is far
As a consequence the most notable differences are in level of irradiation and operating cell tenperature. Ther fore conversion from PV nodule specifications at Standard Test Conditions $\left(25^{\circ} \mathrm{C}\right.$, $1000 \mathrm{~W} / \mathrm{m}^{2}$, air mass 1.5 Global) to BIPV applicable electric system design values is of highest priority as the integration of PV in buildings continues to emerge. The conversion from STC to outdoor open rack conditions is studied in [19] and jndicates an etror of and radiance relation in a graphical way as shown in Fig. 3 where the temperature difference between the PV module and ambient is loaddtaensersionivdithaut the watermark

All BIPV applications differ from the conditions described above. The main differences are to be found in the convective and radiative heat exchanges on the rear side of the PV moduie. These different

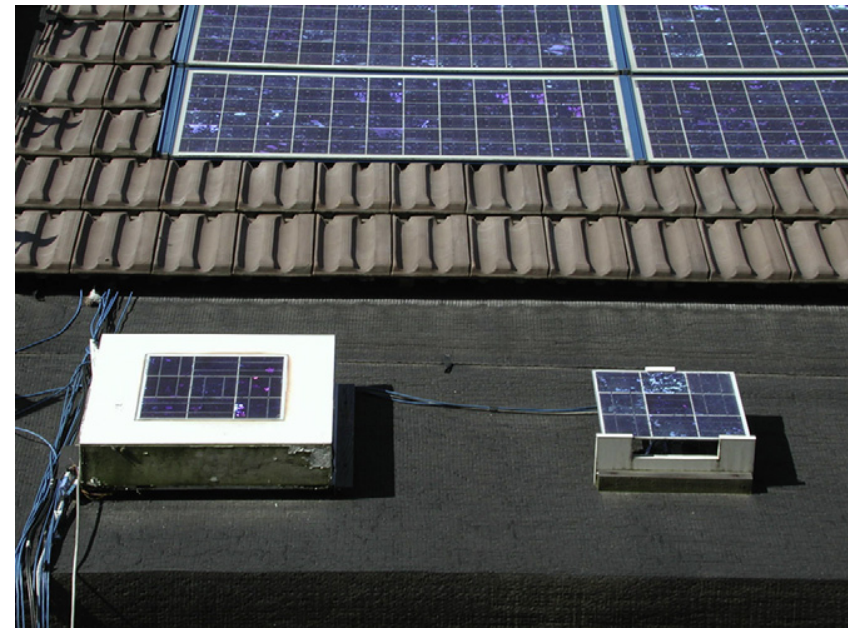

Fig. 4. Different BIPV conditions: integrated roof (top), ICT reference device (on the left) and ventilated reference device (on the right) [7] 

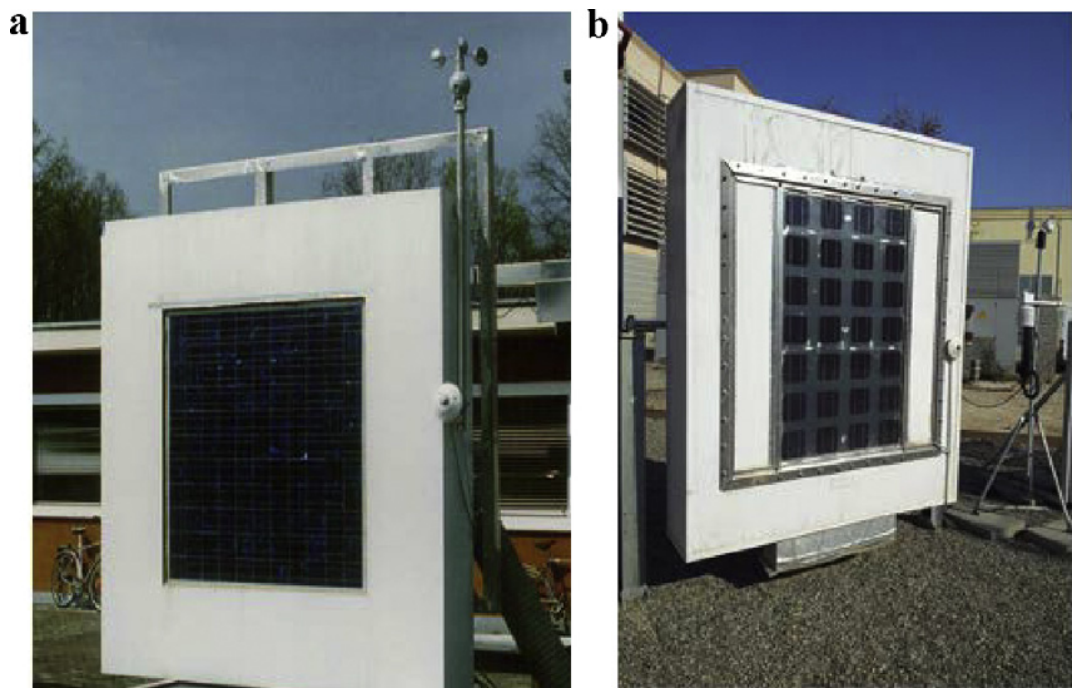

Fig. 5. Front view of the previous experimental set-up. (a) TRE at the JRC in Ispra, Italy; (b) TRE at the PCiTAL in Lleida, Spain.

thermal exchanges cause the NOCT line to move upwards in Fig. 3. Thus even if the NOCT - SRE are available, the outdoor surroundings may cause a different equilibrium mean solar cell junction temperature due to different ground reflectances (from asphalt, grass, grit, etc.) and convective heat exchanges.

In Fig. 3 the standardised reference points are given, according to the STC and NOCT conditions. From the graph, it can be concluded that building integrated PV applications are situated above the NOCT line. The worst condition is when the PV module does not have convective or radiative thermal flows at the rear side. This experimental situation has been created by insulating a PV module with $10 \mathrm{~cm}$ of expanded polystyrene. The measyrement cand tions performed with this spedific module, shown in Fig. 4, are referred to as Insulated Test Condition (ICT). Since standard or guidelines for measurement do not exist at present for these conditions, designers and architects need to calculate with extrapolated data from specifications based on STCand NOCT data supplied by PV module manufacturers. An ICT reference device can assist in defining the

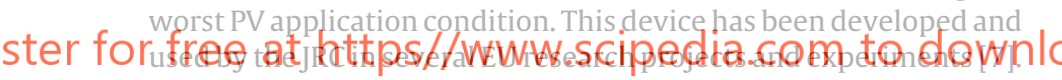

\section{Testing}

A proposal for a Test Reference Environment for double skin BIPV applications is presented.

The first version of a common Test Reference Environment for BIPV systems was designed and built at the EC JRC of Ispra during the IMPACT project in 2001. The experimental set-up is shown in Figs. 5 and 6. It is composed of a wooden box with external sizes of $203 \times 203 \times 46.5 \mathrm{~cm}$ in order to be positioned at the opening of a PASLINK test cell [3]. The internal south-oriented TRE opening allowed the positioning of PV modules with the maximum sizes of $120 \times 120$ and $3 \mathrm{~cm}$ thickness. From the bottom, air could enter and be extracted from the top by means of $20 \mathrm{~cm}$ diameter tubes. The air inlet and outlet sections were initially placed behind the wooden box in order to make caloric experiments possible as a design option for the PASLINK test cell.

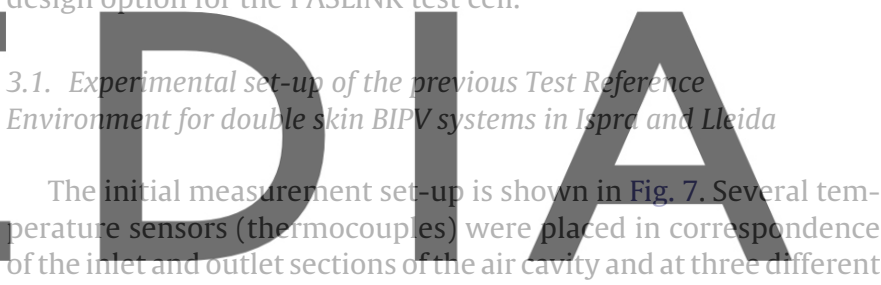
heights on both sides of the insulation layer. No additional sensors ware initially places in correspondepse of the PV modults surface since the referenceps module contaned speenechlis to measure the Voc corresponding temperatures and Isc corresponding irradiation.

Different experiments were carried out within the first TRE setup, testing different PV module compositions under several air flow rates and studying the effect of aluminium transversal fins of $5 \mathrm{~cm}$ length over the air gap rear-facing surface. Dedicated PV modules were also designed [20]. Reference mini-modules were also
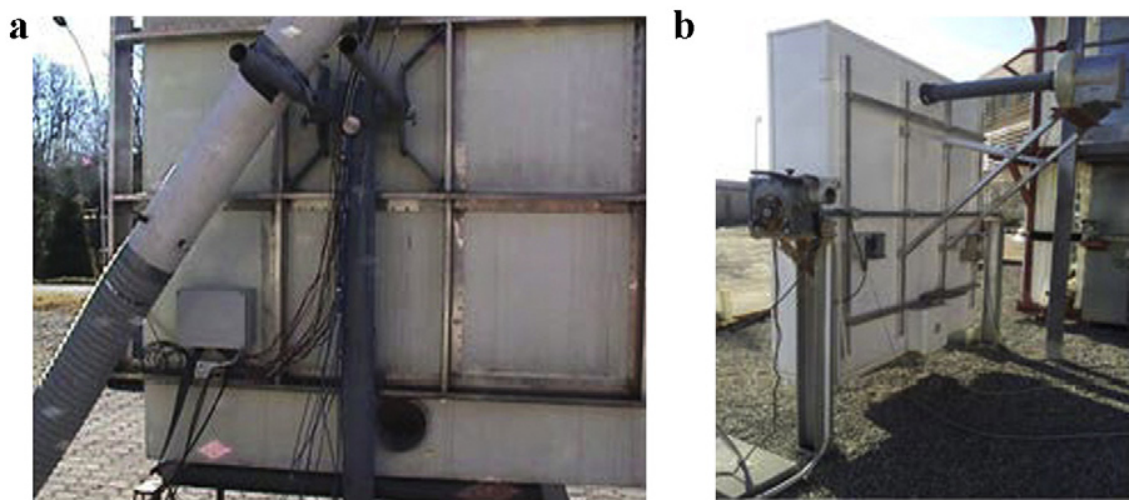

Fig. 6. Rear view of the previous experimental set-up. (a) TRE at the JRC in Ispra, Italy; (b) TRE at the PCiTAL in Lleida, Spain. 


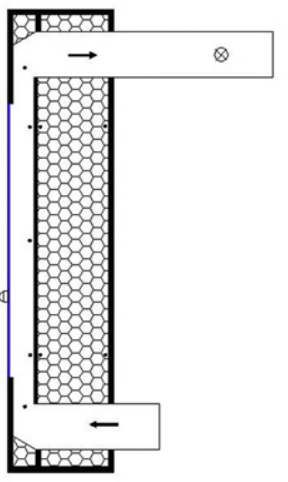

a)

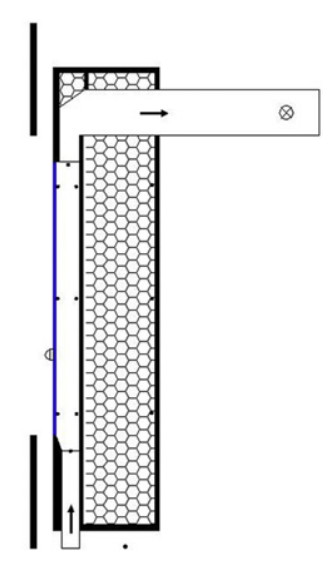

b)

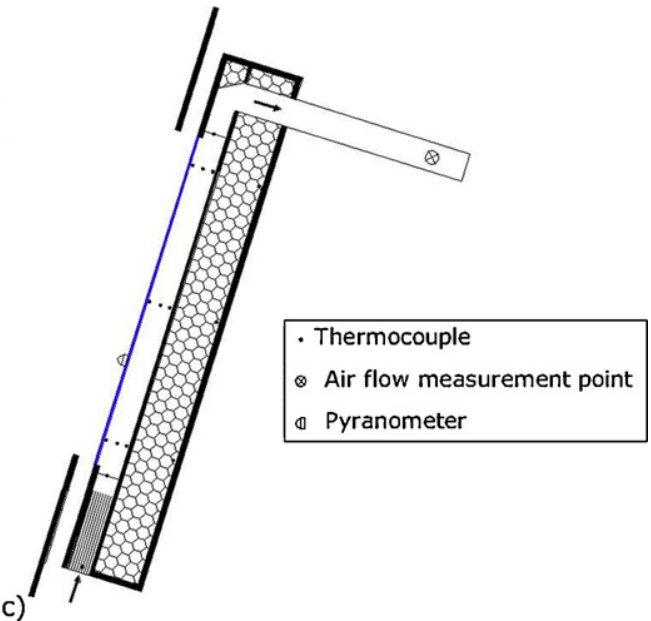

Fig. 7. Lateral cross-section of the previous TRE measurement set-up. (a) First version; (b) second version; (c) third version (variable inclination).

designed for testing the performance of similar PV module compositions in fully insulated and free-rack conditions. Three variables were measured by the device: the irradiation level by measuring the short-circuit current (Isc) over a precision resistance, the open voltage (Voc) and the difference between ambient and PV cells temperature. In Fig. 8 the design of a reference mini-module is shown [7].

Improvements were made to the first TRE set-up. Regarding the geometry, the air-inlet tube was substituted by a $0.1 \mathrm{~m}^{2}$ rectangular opening to guarantee a non disturbed airflow entrance, reducing the measurement uncertainty. During the IMPACT project, JRC laboratory measurements have shown the need for using honey comb at the inlet entrance. In order to frame, the PV module was nounted in line with the white painted façade. External shading devices were placed in correspondence to the air-inlet and outlet to avoid effects of disturbance from sola radiation. Several temperature sensors were also placed in correspondence to the PV module internal surface at three levels (see Fig. 7).

A third version of the TRE was built in 2009 at the Lleida Outdoor were made to the experimental set-up, like the new support structure, which allows for any inclination of the PV module to be tested varying from horizontal to vertical. In addition, the fan was placed at the same height as the outlet tube, reducing corner effects. An array of plastic made cylindrical tubes of $0.5 \mathrm{~cm}$ diameter was placed at the air inlet in order to guarantee a non-disturbed flow pattern (see Fig. 7)

With this third set-up, additional experiments were made testing different materials at the rear-facing surface with the same semi-transparent PV module configuration. The tested materials include a black absorber sheet, a white diffuse reflector sheet and an aluminium specutar reflector sheet. Furthermorø, several airflow regimes for different PV hodule inclinations were tested [12]. 3.2. Description of a standard set-up Environment Feedback from 10-year experimental and modelling work on TRE led to the proposal of a standardised set-up for a Test Reference Environment for double skin applications of BIPV. An impression of

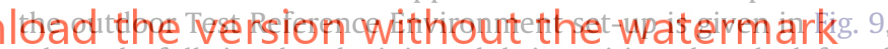
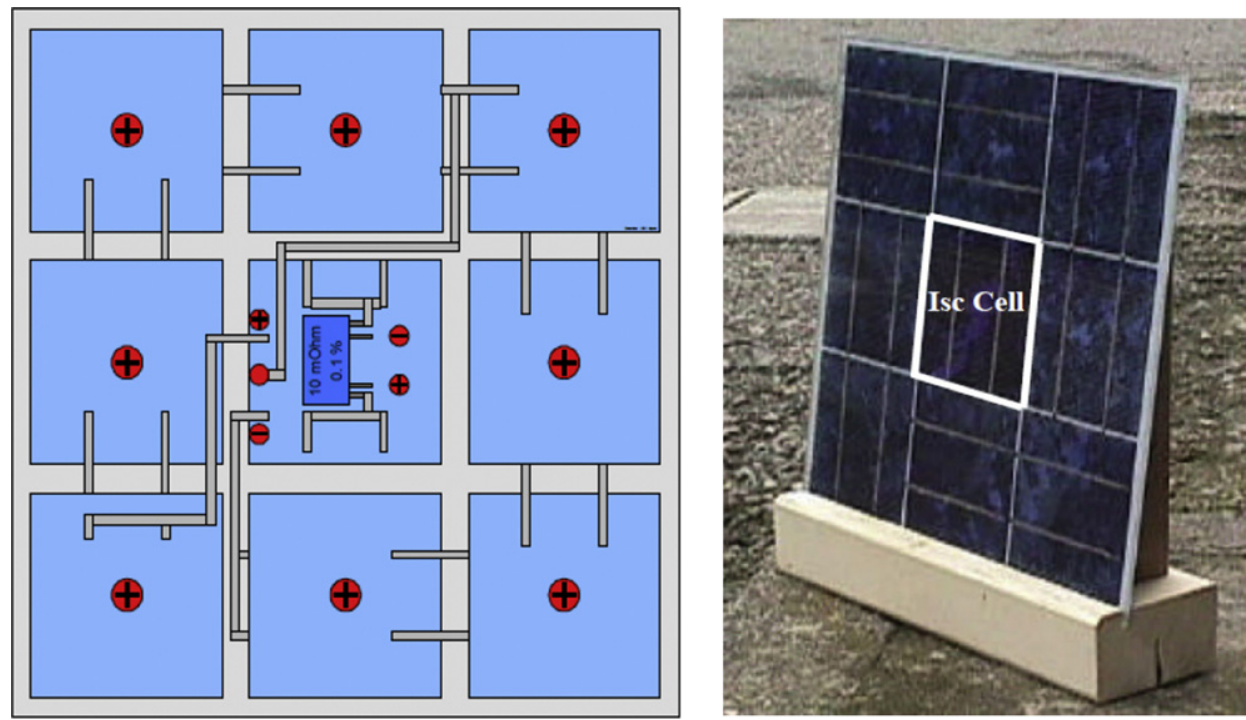

Fig. 8. Design of a reference PV mini-module [7]. 


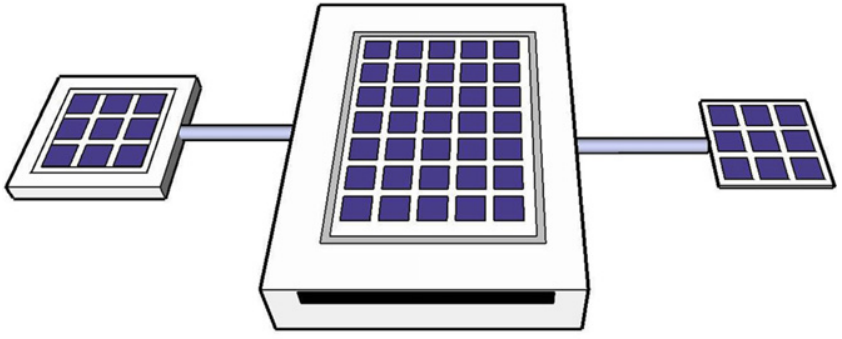

Fig. 9. Schematic presentation of the presented Test Reference Environment and reference mini-modules.

the free-rack mini-module on the right. Below an explanation is presented on geometry, instrumentation, experimental set-up and calibration issues.

\subsubsection{Geometry}

Requirements for the TRE geometry and materials are given below.

The south-oriented opening should allow the positioning of PV modules with maximum sizes of $1.2 \times 1.2 \mathrm{~m}$. The weather resistant wooden box should be made by white-painted wooden panels (from 1.5 to $3 \mathrm{~cm}$ thick). In order to take on adiabatic conditions behind and to the lateral sides of the air channel, the insulation layer of the box should be at least $30 \mathrm{~cm}$ thick of expanded polystyrene (EPS) (thermal conductivity $0.032-0.037 \mathrm{~W} / \mathrm{mK}$ ). The error due to the conduction of these layers is less than $0.5 \%$.

The support structure should allow any possible inclination to be tested (from $15^{\circ}$ to vertical). The air is extracted from the top by means of a variable speed fan in order to test different air gap flow rates.

The PV module has to avoid shadowing effects. A recommended in correspond effects of disturbance from may be white painted aly in order to protect the i wooden box should be ar
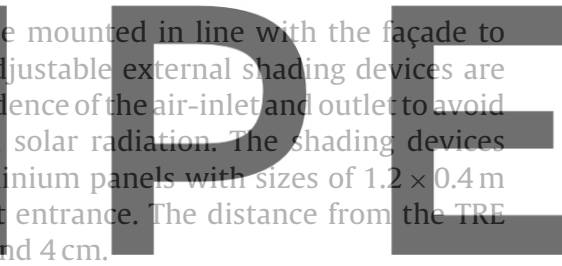

The air should enter from the bottom by means of a rectangular entrance section of dimension $120 \times 10 \mathrm{~cm}$; honey comb structure

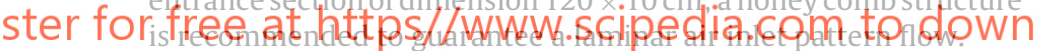

It is recommended to install a small inclined roof on the top of the box to avoid water stagnation or infiltration that could reduce disturbance from solar radiation as well.

\subsubsection{Instrumentation}

In general, to reduce the resulting error from analysis, the highest attention has to be given to sensor measurement accuracy and its positioning. The measured signal has to represent the physical meaning and should correspond with model input, therefore disturbance from solar radiation should be avoided by shielding temperature sensors. A weather station nearby could provide important data for analysis, such as temperature, solar radiation, wind speed and direction and relative humidity but these data should be applied for control or back-up purposes only. In principle, all required input data for the analysis process has to be measured next to the TRE.

The following requirements are considered for the TRE instrumentation and sensors:

- Surface temperatures of the PV module and the rear-side material have to be measured at least at three different heights (in correspondence to the bottom, top and middle of the air cavity). For the PV cells temperature it is preferable to measure in the centre of the cell to avoid border effects. Recommended contact sensors are stick-on type T thermocouples or PT100 (minimum accuracy of $0.3^{\circ} \mathrm{C}$ ).

- Air gap temperatures have to be measured at least at three different heights (in correspondence to the bottom, top and middle of the air cavity) (see Fig. 10). Cylindrical shading protections should be used in correspondence of these sensors to avoid effects from direct solar radiation. It is suggested to use thermocouple piles to measure the temperature difference between inlet and outlet section corresponding to the bottom and top of the PV module. Recommended sensors are type $\mathrm{T}$ thermocouples. Special small devices (like copper plates of $1 \mathrm{~cm}^{2}$ ) may be placed to give some thermal mass to the sensors to obtain a smoother temperature reading. Additional air temperatures can be measured in the outlet tube by an array of thermocouples.

- Regarding the air flow rate measurements, it is strongly recommended to follow a standardised method for air flow measurements in tubes [12]. For the correct application of this method, the straight outlet duct should have a length of at least 5 times the diameter before the measuring section. Regarding the air velocity measurements, it is recommended to use omnidirectional hot wire anemometer for air velocity lower than 0.4 $\mathrm{m} / \mathrm{s}$ and miniature cup anemometers for higher speeds.

It is recommended to use a calibrated pyranometer for the solar irradiance measurements. The pyranometer has to be placed in line with the façade and preferably at middle height of the PV module. The minimum resolution required is $1 \%$ of the readings. Ambient air temperature has to be measured with ventilated sensors shielded from solar radiation; it is preferable to measure at least in two different positions in respect to the TRE: behind, in the shading of the TRE wooden box and in correspondence to the air inlet section. Measuring the ambient temperature at several positions would guarantee the measurement of the correct signals that correspond to the energy flows due to the BIPV system
boundary conditions. Some thermal mass cquld be given to these
sensdrs.
Wind direction and speed might be measured with c cup-type
anemometer placed about $5 \mathrm{~m}$ in front of the TRE and at PV mod-
ule level ( $2 \mathrm{~m}$ height).
Elect icity prodtuction: three different possibilities are considered:

\section{PV module connected with a micro-inverter:

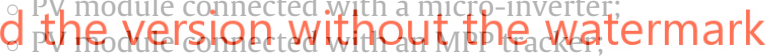

\section{PV module that enables switching from Voc to Isc with a special}

electrical circuit ( $I-V$ curve generation); it is preferable to have the PV module designed in such a way that it contains specific cells in open circuit (to track also the PV cells temperature), and in short circuit (for the additional assessment of the absorbed solar irradiance).

\subsubsection{Experimental set-up}

Data have to be recorded with 1-min intervals in order to study the dynamic effects from solar radiation and wind.

A minimum test period of $24 \mathrm{~h}$ is required, thus including the night time period. In this way the energy balance during the night can be assessed as well. Selected days for evaluation have to fulfil several requirements. Series of days with similar solar irradiance distribution but different temperatures and wind speeds have to be considered for assessment purposes. Both sunny and cloudy days have to be considered.

Since data from test-days should contain enough information, a minimum incident solar energy of $5 \mathrm{kWh}$, during one day and at the same inclination of the PV module, has to be reached for the acceptance of the test. During this measurement period, wind speed should be stable enough: data could be averaged at 8 -h intervals during one day period and if the average values differ more than 

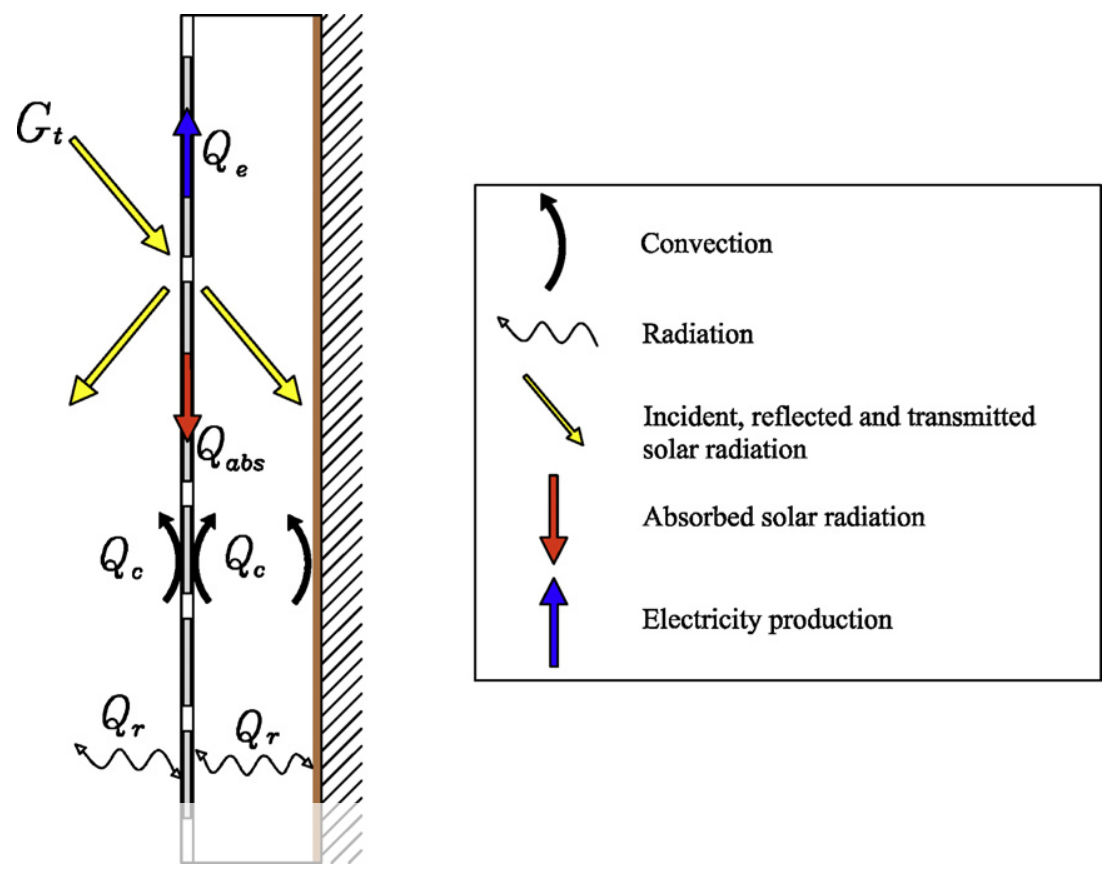

Fig. 11. Schematic view of the different energy flow processes within TRE.

is normally non linear, both UWT and UHF boundary conditions are approximations of the reality.

It follows the overall energy balance equations for each layer of the system, considering the electrical analogy model [22]:
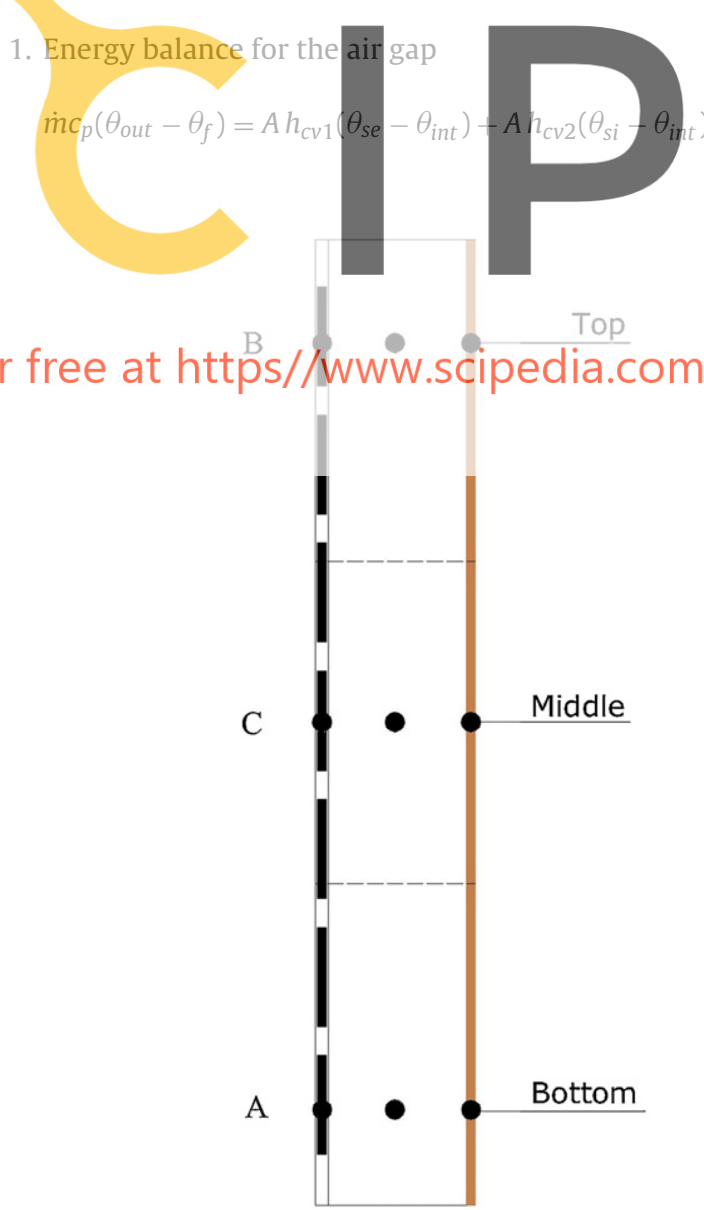

Fig. 12. Scheme of the estimation set-up.
2. Energy balance for the external surface of the air gap

$$
\varphi_{s e}=\frac{\left(\theta_{\text {ope }}-\theta_{s e}\right)}{R_{e}^{*}}+N_{i}^{*} \alpha_{e s t} G_{t}=\frac{\left(\theta_{s e}-\theta_{\text {int }}\right)}{R_{c v}}+\frac{\left(\theta_{s e}-\theta_{s i}\right)}{R_{r d}}
$$

3. Energy balance for the internal surface of the air gap

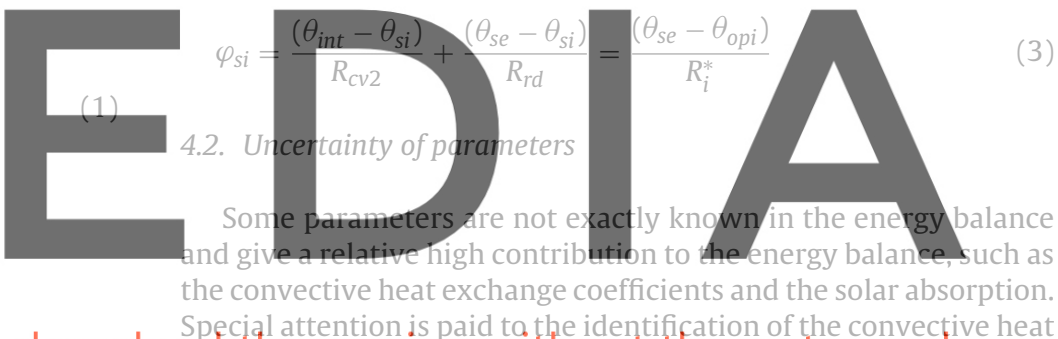
Special attention is paid ta the identification of the convective heat

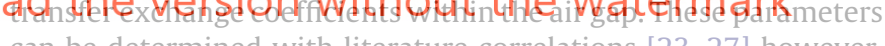
can be determined with literature correlations [23-27] however, they are difficult to define, especially for laminar flow.

The convective heat transfer coefficient at the exterior surface of the PV module is normally defined as a linear or exponential function of wind speed [28-30], but only for high wind speed.

Regarding the solar absorption of the PV module, especially if a semi-transparent PV module is tested, it is important to distinguish between the absorption of the opaque (PV cells) and the transparent area by considering two different values [9] or an equivalent weighted value for $\alpha_{e s t}$. In order to take into account the reflective properties of the external surface of the PV module, the solar absorption can be expressed as a function of the angle of incidence [31]. It is also possible to take into account internal reflections with the net transfer method [32].

\subsection{Recent analysis work with data from TRE}

Different authors [10,11,13] developed identification models that fit the data by identifying suitable values to the aforementioned physical parameters of the system.

Jiménez et al. [10] developed several grey-box models for the energy transfer evaluation of a double skin BIPV façade based on experimental data from the second version of the TRE. The outweighing factor of grey-box models is the possibility to combine 


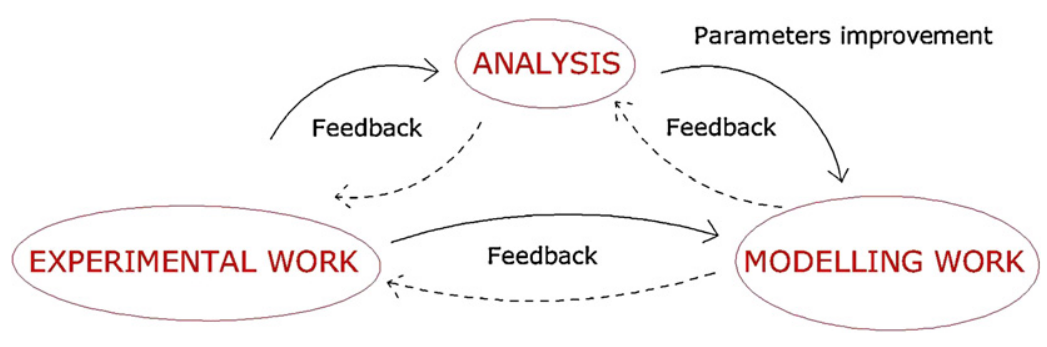

Fig. 13. Overview of the processes involved in the assessment of the energy performance.

prior physical knowledge of the system and statistics. The temperature of the PV module was chosen as the state and the output variable and different linear and non-linear models were presented. It was found that a non-linear single-state model was the most suitable for describing the dynamics convective and radiative of the BIPV energy balance.

In [11], the model formulated in [10] was applied with different experimental data from the second version of the TRE, where transversal fins were placed in the air gap. Within this work, an exponential relation between the wind speed and the ambient convective coefficient was correctly identified for the specific set-up.

Lodi et al. [13] developed an extension to the models described in [11], identifying several convective heat exchange coefficients for different air flow rates using non-linear grey-box models based on experimental data from the third version of TRE. The identified Nusselt numbers are in the range of 10-90 for Reynolds numbers varying from 1000 to 30,000.

5. Prediction and modelling work process. The model showed a good agreement with the measured values of $\theta_{s e}$, while for $\theta_{s i}$ a disagreement was found between predicted and measured values. An error of less than $5 \%$ was found in the prediction of the electricity production. It was found that the air inlet tube created strong local turbulences that locally increased the convective heat transfer coefficients.

Based on these results, several changes of the TRE geometry and set-up were considered and implemented for improved experiments and high quality data.

Based on the third version of the TRE experimental data, Cipriano [32,13] validated another TRNSYS model. UHF boundary conditions were considered in this work and a single control volume was established for the energy balance within the air gap. The heat conduction within the solid layers was modelled using a one dimension finite element discretisation approach and 10 nodes were considered for each energy exchange layer. A first validation was carried out in [13], thus a more precise refinement of the convective heat exchange coefficient correlations was necessary. It is important that the model developed for double skin appliModelling work intends to models with identified or as assumec phenomena or a process.

Over the last 10 years, the used for validation of modelling work by

5.1. Recent modelling work with data from TRE

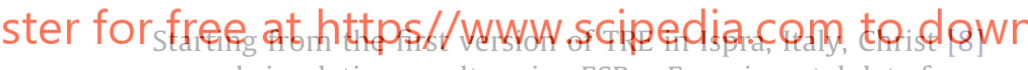
compared simulation results using ESP-r. Experimental data from this first version of TRE were compared with data from two different PV-Hybrid-Pas test cells located in Stuttgart, Germany and in Athens, Greece. The developed program used the air gap heat exchange coefficients from literature. When predictions did not correspond with the experimental data, a set of heat transfer coefficients was assessed by a parameter fitting and optimisation technique. The conclusions of the author were that simulations of high laminar flow using heat transfer coefficients calculated with standard correlations seem to deliver appropriate predictions as long as the temperature differences between the PV module and the air are lower than $35^{\circ} \mathrm{C}$. For lower airflow rates and higher temperature differences, the actual heat transfer coefficients were found higher than the calculated ones probably because of the higher uncertainty. Therefore a more detailed study of the convective heat exchange coefficients was planned for future work.

Experimental data from the first version of TRE were used also by Gandini $[9,22]$ to validate a new TRNSYS model. An electrical analogy model which includes the PV module conduction resistance was used. Within this study, data from tests carried out over 4 different PV modules under several air flow rates were tested. In order to investigate the heat transfer coefficients within the air gap, a three-dimensional model of the air gap was developed using FLUENT 6.2.0 software, giving adjusted parameters for the analysis the overall building in order to analyse the feasiblity of the investment. The procedure for investigating the ability to model the test component is divided into three stages: calib/ation (alignment of the test caling (simulationent ent, using the "Intcorated Performance View [18]" standardised calculation) and replication (repeating the simulations with different locations). Within the outlined procedure, the assumption

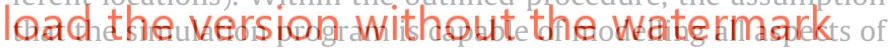
the building is done. Therefore, within the validation process, this assumption is verified.

\subsection{Feedback between evaluation and modelling work}

The evaluation and modelling processes should provide a reciprocal feedback to each other for high quality performance characterisation. In fact, results from evaluation can be an input for model validation work but also modelling work gives input to evaluation for model optimisation and for a proper design of the experimental work (see Fig. 13). This approach has led to the third and improved version of the TRE and to the definition of an harmonised set-up.

\section{Conclusions and recommendations}

After more than 10 years of development in different European research projects, a standard Test Reference Environment for double skin applications of BIPV Systems is presented in this paper. Using this reference environment for PV modules integrated in facades or roofs, different PV module configurations can be tested changing the boundary conditions. The paper suggests also a common way of evaluating the data obtained from the experiments. Mini-modules are proposed to get the required information for 
evaluation. These modules give an indication of the BIPV performance range, introducing an additional point for reference. The first version of the TRE was developed during the IMPACT project and improvements were made during the last 10 years at the JRC and Lleida. Several thermal processes are considered in the energy balance and several non-linear parameters are identified by estimation. Important improvements in the controlled outdoor experimental set-up and data evaluation have been made based on identifying from analysis and modelling work. Different authors successfully developed numerical models, using experimental data from the TRE and an overview of the most important results is presented as well.

In order to harmonise experimental work for the assessment of electrical as well as thermal characteristics of photovoltaic systems in the building envelop, it is recommended to define a common outdoor test environment as a proposal is presented herewith. Presently the definition and assessment of electrical performance data is defined in IEC standards but do not cover BIPV applications. Harmonisation could be further developed in EU projects to support the definition of international standards.

The definition of an Insulated Test Condition for PV modules as described in this paper would support the indication of the performance range for BIPV applications. The ICT point could be inserted into the IEC 61215, which now includes only STC (laboratory conditions) and NOCT (free-rack mounted conditions) points.

\section{Acknowledgement}

This work is financially supported by a grant of the Spanish Ministry of Science and Innovation, FPU program (ref. AP2008-01801).

\section{References}

[1] European Parliament, Directive 2010/31/EU of the European Parliament and of the Council of 19 May 2010 on the energy performance of buildings, 2010.

[2] D. van Dijk, R. Versluis, PV-HYBRID-PAS: results of thermal performance assessment, in: Proceedings of the 2nd World Conference and Exhibition on Photovoltaic Solar Energy Conversion, Vienna, Austria, 1998.

[3] P.H. Baker, H.A.L. van Dijk, PASLINK and dynamic outdoor testing of building components, Building and Environment 43 (2008) 143-151.

[4] J.C. Jol, J.J. Bloem, B.M. Cross, M. Sandberg, K. Wambach, W. Wiesner, et al., Towards a CE mark for PV building integrated systems, in: Proceedings of the 16th European Photovoltaic Solar Energy Conference, Glasgow, UK, 2000

[5] International Standard IEC, 61215, Crystalline Silicon Terrestrial Photovoltaic (PV) Modules - Design Qualification and Type Approval, 2005.

[6] J.R. Bates, U. Blieske, J.J. Bloem, J. Campbell, F. Ferrazza, R.J. Hacker, et al., Building implementation of photovoltaics with active control of temperature, in: Proceedings of the 17th European Photovoltaic Solar Energy Conference, Munich, Germany, 2001.

[7] J.J. Bloem, The JRC PV reference module for an energy rate indicator, in: Proceedings of the 16th European Photovoltaic Solar Energy Conference, Glasgow, UK, 2000.

[8] F.H.M. Christ, Comparison of measured and predicted data for PV hybrid systems, Master's thesis, University of Strathclyde Department of Mechanical Engineering, 2001.

[9] A. Gandini, Analisi numerica delle facciate fotovoltaiche a "doppia pelle", Politecnico di Milano, 2003.
[10] M.J. Jiménez, H. Madsen, J.J. Bloem, B. Dammann, Estimation of non-linear continuous time models for the heat exchange dynamics of building integrated photovoltaic modules, Energy and Buildings 40 (2008) 157-167.

[11] N. Friling, M.J. Jiménez, J.J. Bloem, H. Madsen, Modelling the heat dynamics of building integrated and ventilated photovoltaic modules, Energy and Buildings 41 (2009) 1051-1057.

[12] C. Lodi, J. Cipriano, J.J. Bloem, D. Chemisana, Design and monitoring of an improved test reference environment for the evaluation of BIPV systems, in: Proceedings of the 25th European Photovoltaic Solar Energy Conference, Valencia, Spain, 2010, pp. 5135-5140.

[13] C. Lodi, J. Cipriano, P. Bacher, H. Madsen, Modelling the heat dynamics of a monitored Test Reference Environment for BIPV systems through deterministic and stochastic approaches, in: International Workshop on "Whole Building Testing, Evaluation and Modelling for Energy Assessment", Technical University of Denmark, Lyngby, Denmark, 2011.

[14] IEA ECBCS, Annex 58 Reliable Building Energy Performance Characterisation Based on Full Scale Dynamic Measurements. http://www.ecbcs.org/ annexes/annex58.htm.

[15] L. Vandaele, P. Wouters, J.J. Bloem, W.J. Zaaiman, Combined heat and power from hybrid photovoltaic building integrated components: results from overall performance assessment, in: Proceedings of the 2nd World Conference and Exhibition on Photovoltaic Solar Energy Conversion, Vienna, Austria, 1998.

[16] J.J. Bloem, P.H. Baker, Building integration issues for photovoltaics, in: Proceedings of BIAT - Technical Innovation in Design and Contruction, Dublin Castle, 2000.

[17] A. Jager-Waldau, PV STATUS REPORT 2011, JRC Scientific and Technical Reports, European Union, 2011

[18] J.J. Bloem, P.H. Baker, P.A. Strachan, Energy performance of buildings and the integration of photovoltaics, in: International Conference Improving Energy Efficiency in Commercial Buildings (IEECB’04), Frankfurt, Germany, 2004.

[19] R.P. Kenny, G. Friesen, D. Chianese, A. Bernasconi, E.D. Dunlop, Energy rating of PV modules: comparison of methods and approach, in: Proceedings of the 3rd World Conference on Photovoltaic Energy Conversion, Osaka, Japan, 2003.

[20] J.J. Bloem, W. Zaaiman, C. Bucci, V.R. Nacci, Proposal for a PV reference module and a test reference environment for BIPV applications, in: Proceedings of the 16th European Photovoltaic Solar Energy Conference, Glasgow, UK, 2000.

[21] INIVE EEIG, Stimulating increased energy efficiency and better building ventilation, Brussels, Belgium, 2010, ISBN 2-930471-31-X.

[22] J.J. Bloem, Evaluation of a PV-integrated building application in a wellcontrolled outdoor test environment, Building and Environment 43 (2008) 205-216.

[23] R.K. Shah, A.L. London, Laminar flow forced convection in ducts, in: Advances in Heat Transfer, Academic, New York, NY, 1978.

[24] F. Incropera, D.P. De Witt, Fundamentals of Heat and Mass Transfer, John Wiley \& Sons, New York, 1985.

[25] U. Eicker, Solar Technologies for Buildings, Wiley, Chichester, 2003.

[26] S. Ito, M. Kashima, N. Miura, Flow Control and Unsteady-State Analysis on Thermal Performance of Solar Air Collectors, Journal of Solar Energy Engineering 128 (2006) 354-359.

[27] L.M. Candanedo, A. Athienitis, K.W. Park, Convective Heat Transfer Coefficients in a Building-Integrated Photovoltaic/Thermal System, Journal of Solar Energy Engineering ASME 133 (2011), 021002-1-021002-14.

[28] S. Sharples, Full-scale measurements of convective energy losses from exterior building surfaces, Building and Environment 19 (1984) 31-39.

[29] J.A. Duffie, W.A. Beckman, Solar Engineering of Thermal Processes, 3rd ed., Wiley, 2006.

[30] F.L. Test, R.C. Lessmann, A. Johary, Heat Transfer During Wind Flow over Rectangular Bodies in the Natural Environment, ASME Transactions, Journal of Heat Transfer 103 (1981) 262-267.

[31] J.J. Bloem, R. Versluis, M. Tijssen, W.J. Zaaiman, Thermal modelling and testing results of the reference component, Technical Report PV-Hybrid Pas, JRC Ispra, Italy, 1997.

[32] J. Cipriano, C. Lodi, D. Chemisana, G. Houzeaux, H. Perpiñán, Development and characterization of semitransparent double skin PV facades, in: Proceedings of the 1st International Conference on Solar Heating, Cooling and Buildings, Lisbon, Portugal, 2008 